EPiC Series in Engineering
Volume 3, 2018, Pages 1902-1910
HIC 2018. 13th International
Conference on Hydroinformatics

\title{
Serial Application of SWAT and CE-QUAL- W2 to Predict Water Quality Dynamics in the Basin and Lake of the Yongdam Dam, Korea to Analyze Climate Change Effects
}

\author{
Dongil Seo ${ }^{1}$, Jongtae Park ${ }^{2}$ and Youngmin $\mathrm{Koo}^{1}$ \\ ${ }^{1}$ Env. Eng., Chungnam National Univ., 99 Daehak-Ro Yuseong-gu, Daejeon, Republic of Korea \\ ${ }^{2}$ GeoSystem Research Corporation, \#306, 172 LS-ro, Gunpo-si, Gyeonggi-do, Republic of Korea \\ seodi@cnu.ac.kr, whdxogo@naver.com, crownkoo@daum.net
}

\begin{abstract}
Long term changes in pollutant loadings and water quality of the Yongdam Lake due to climate changes were estimated by using a basin model and a surface water quality model in series. Two Representative Concentration Pathways scenarios, RCP4.5 and $\mathrm{RCP} 8.5$, that stabilize radiative force at $4.5 \mathrm{~W} / \mathrm{m} 2$ (significant reduction) and $8.5 \mathrm{~W} / \mathrm{m} 2$ (current trend), respectively, were applied and their impacts were predicted. The SWAT model was selected in the basin to predict flow rates and loadings of major pollutants to the lake. Then, the CE-QUAL-W2 model was used to estimate water levels and water concentrations in the study lake. Both models were applied for 6 years from 2010 to 2015 and the latter three years were used for calibrations discarding the first three year warming up periods' results. Using the both models, future flow rate and water concentration were estimated for 80 years from 2016 to 2095 . The RCP 8.5 scenario application results shows future flow rate and water quality concentrations will be increased in flood seasons and decreased in dry seasons. This result indicates that drought and flood will become more serious and also their effects on water quality will become more serious in the future. The RCP4.5 scenario showed greater increase in flow rates and TSS and TP concentrations than RCP8.5 scenarios despite the significant reduction in green house gas. This may be caused by increased air temperature followed by increased evapotranspiration that led surface runoff reduction in the basin area of the RCP8.5. This study suggests that dependent on characteristics of local climate change effect, impacts on the environmental may be different. Also, temporal distributions of precipitation pattern during simulation period and also in a year must be investigated thoroughly as simple arithmetic averages may not reflect detailed phenomena appropriately.
\end{abstract}




\section{Introduction}

The Intergovernmental Panel on Climate Change (IPCC, 2014) published the fifth assessment report (AR5) and suggested four RCP (Representative Concentration Pathway) scenarios from the RCP8.5 that reflects BAU (business as usual) and to the RCP2.6 that reflects the best possible case (Recoverable) based on greenhouse gas reductions and resultant $\mathrm{CO} 2$ concentrations in the atmosphere. The RCP 8.5 scenario predicts temperature increase of $3.7^{\circ} \mathrm{C}$ and sea level increase of $0.63 \mathrm{~m}$ by 2100 if we do not have any reduction on greenhouse gas. Each country has tried to be prepared environmentally and socio-economically by evaluating vulnerability and adaptation capacity against different climate change scenarios. However, an appropriate quantification method is necessary for such $a b$ estimation for quantity and quality of water in the future conditions. Modelling is a good tool for this purpose. In this study, impacts on water quality and quantity changes from climate changes were estimated by using the SWAT (Neitsch, S. L.; Arnold, J. G.; Kiniry, J. R.; Williams, J. R.; 2011) model in the basin and the CE-QUAL-W2 (ColeT. M. \& WellsS. A., 2016) model for inside the Yongdam Lake.

\section{Methods}

\subsection{Study Area}

The Yongdam Lake and its basin area, as shown in Figure 1, are located in the most upstream part of the Geum River, the lake and river are fourth and third largest in Korea. The lake was formed as the Yongdam Multipurpose Dam was completed in 2001 for water supply, flood control and hydro power generation. The storage capacity of lake is $815 \times 106 \mathrm{~m}^{3}$ and its basin area is about $930 \mathrm{~km}^{2}$.

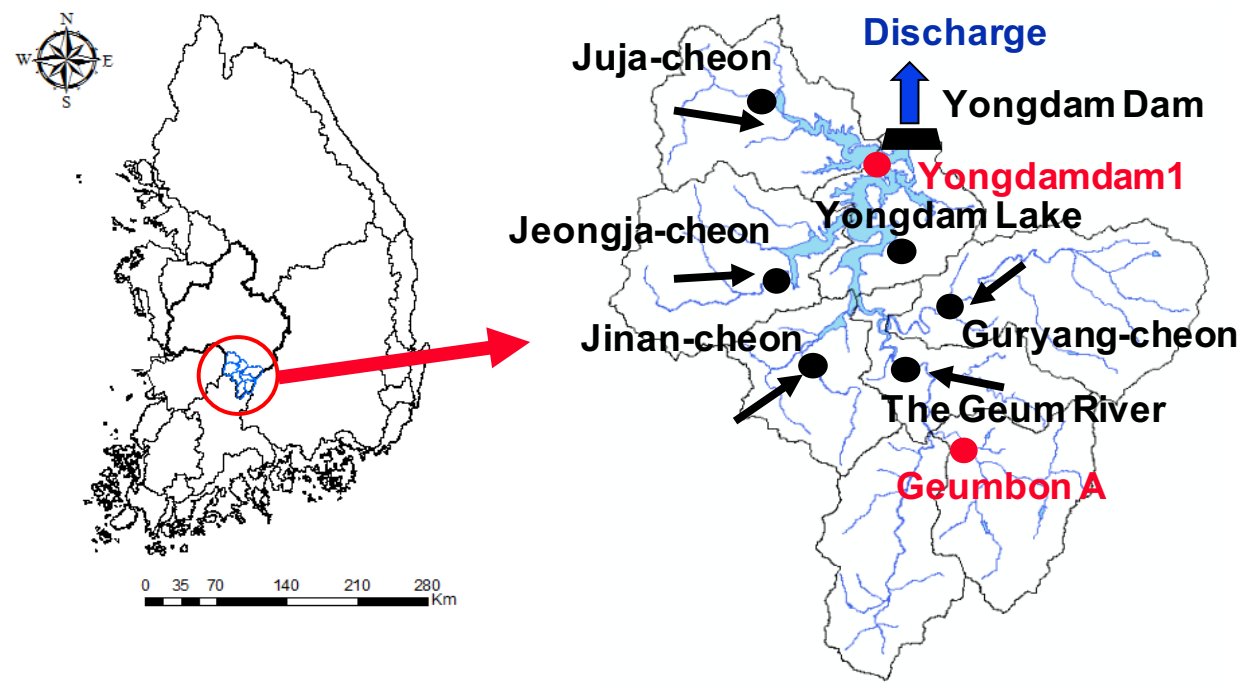

Figure 1: Locations of the Yongdam Lake and Its Basin Area, Major Tributaries (Black points with arrows) and Monitoring Stations used for Model Calibration (Red) in this study 


\subsection{Climate Change Scenarios}

Table 1 shows the four RCP scenarios and respective increases of temperature and mean sea level in 2100 (IPCC, 2014). In this study, two scenarios, RCP 4.5 and RCP8.5, were chosen. Korea Meteorological Agency (KMA) downscaled the RCP scenarios for local regions of Korea. Figure 2 shows the downscaled scenario for "Yongdam" area by KMA (KMA, 2014).

\subsection{Hydrological and Water Quality Modelling}

The SWAT (Soil and Water Analysis Tool) model was used to generate hydrological and water quality information at outlets of major tributaries of the study basin. Then this information was used as boundary conditions of the CE-QUAL-W2 to estimate water transport and water quality changes in the lake as shown in Figure 3. All the necessary data to construct model inputs were obtained from Korean governmental database systems (KMA, 2014) (NIER, 2017) (WAMIS, 2017). Both models were applied for 6 years between 2010 and 2015 as described earlier. The first three-year model run results of 2010 2012 were discarded by assuming as warming up period. The model calibrations of both models were concentrated for the latter three-year period 2013 2015 by comparing the model results against field observations.

\begin{tabular}{lrr}
\hline RCP Scenario & $\begin{array}{r}\text { global warming increase } \\
\left.\mathbf{(}^{\circ} \mathbf{C}\right)\end{array}$ & $\begin{array}{r}\text { global mean sea level (m) } \\
\text { increase }\end{array}$ \\
\hline RCP2.6 (Recoverable) & $1.0(0.3 \sim 1.7)$ & $0.40(0.26 \sim 0.55)$ \\
RCP4.5(Significant & $1.8(1.1 \sim 2.6)$ & $0.47(0.32 \sim 0.63)$ \\
Reduction) & & \\
RCP6.0 (Some Reduction) & $2.2(1.4 \sim 3.1)$ & $0.48(0.33 \sim 0.63)$ \\
RCP8.5 (Business As Usual) & $3.7(2.6 \sim 4.8)$ & $0.63(0.45 \sim 0.82)$ \\
\hline
\end{tabular}

Table 1: Increase in Global Temperature and Mean Sea Level for Climate Change Scenarios in 2100

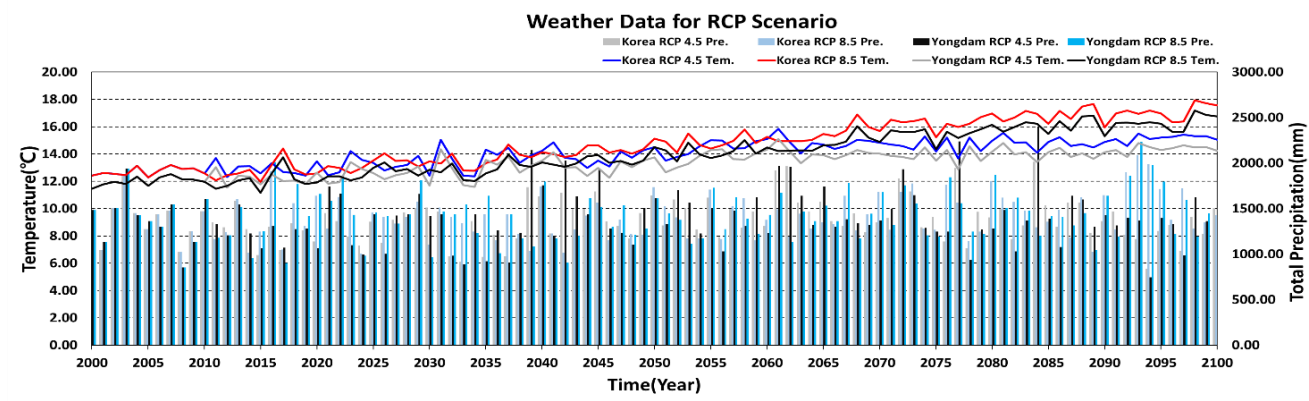

Figure 2: Temperature and Precipitation Changes due to Climate Change for Korea and the Study Area 


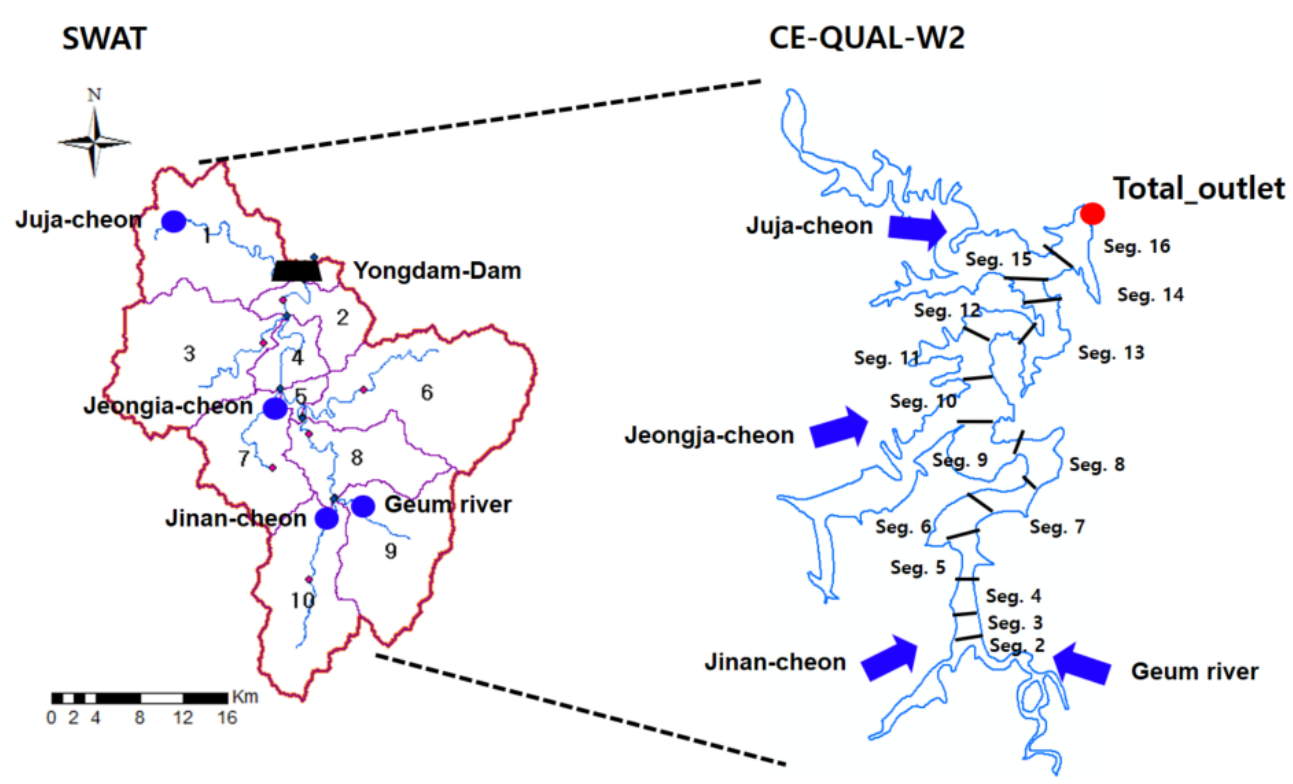

Figure 3: Conceptual Schematic of Serial Modelling of Basin Area and The Yongdam Lake, Korea.

\section{Results and Discussions.}

\subsection{Calibration Results}

Figure 4 and Table 2 show calibration results and error analysis results, respectively, of the SWAT model at the outlet of main tributaries of the Yongdam Lake. The "Geumbon A" monitoring station was used as a calibration site for SWAT model. While calibration results for flow rate seem to be reasonable, calibration results for water quality concentrations are relatively poor. This may be caused by limitation of input data for water quality variables such as nonpoint source pollutants load information. However, it seems calibration results reflect water quality variation trend reasonably well and it was regarded that the results can be used to analyse the macroscopic future trends in this study. Separate calibration was performed for water level and water quality concentrations in the lake using monitoring results in the "Yongdamdam 1" stations as shown in Figure 5 and Table 3. Initial calibration parameters and constants were based on studies of Ahn et al. (AhnS. R, KimH. S., YoonW. S., KimJ. S., 2013) and Chung et al. (ChungW. S, ParkH. J., KimY., YoonW. S., 2007) and further refinement was made by trial and error method. 
Serial Application of SWAT and CE-QUAL-W2 to Predict Water Quality Dynamics ... D. Seo et al.
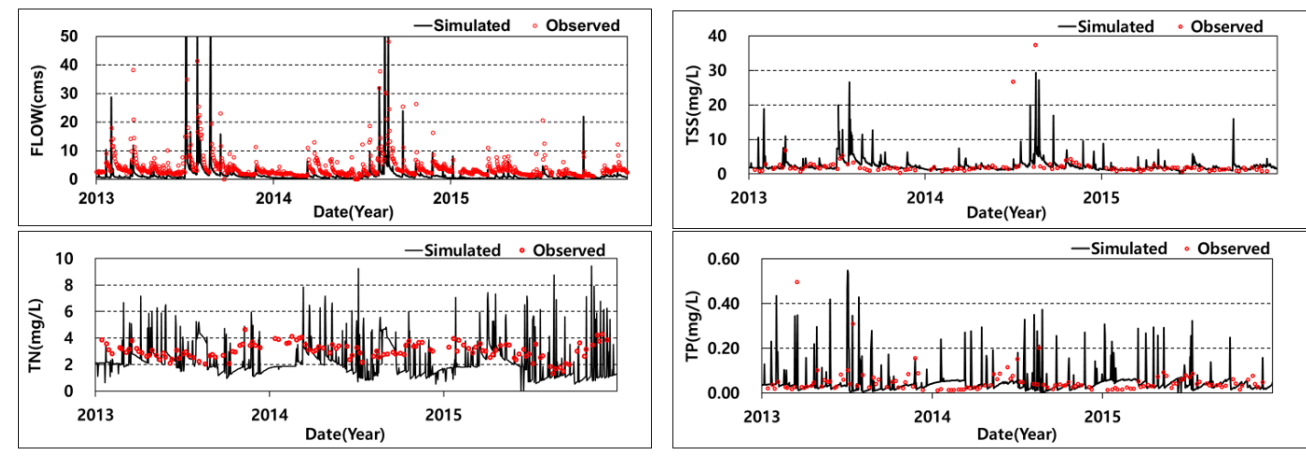

Figure 4: Calibration results of SWAT model for the main inflow of the Yongdam Lake.
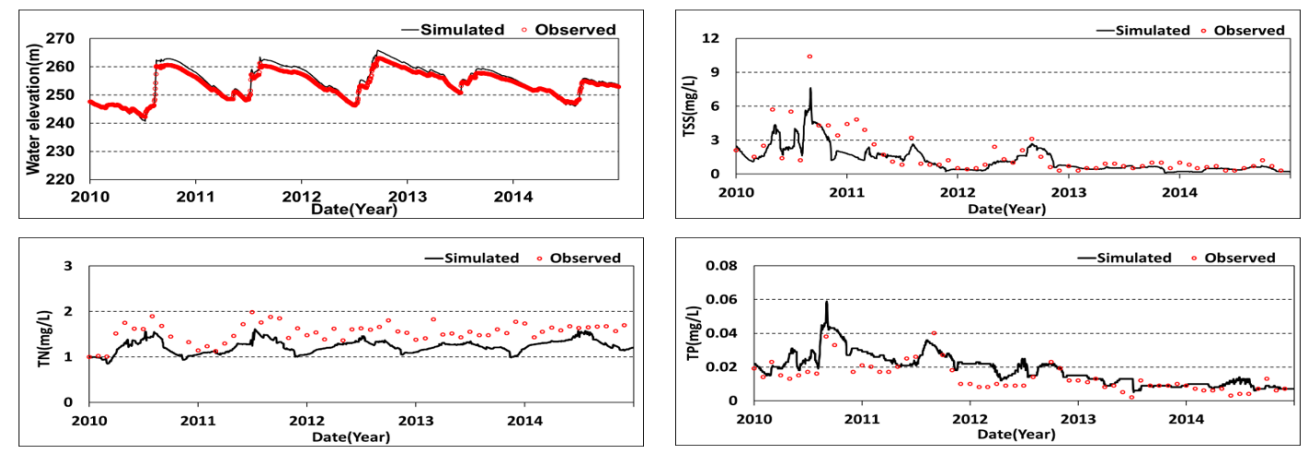

Figure 5: Calibration of CE-QUAL-W2 model for "Yongdamdam 1" station in the Yongdam Lake.

\begin{tabular}{lrlll}
\hline & $\begin{array}{r}\text { Water } \\
\text { Elevation }\end{array}$ & TSS & TN & TP \\
\hline $\mathbf{R}^{2}$ & 0.86 & 0.40 & 0.13 & 0.20 \\
$\mathbf{N S E}$ & 0.64 & 0.22 & -0.35 & -0.09 \\
$\mathbf{R M S E}$ & 6.11 & 2.42 & 1.67 & 0.07 \\
\hline
\end{tabular}

Table 2: Calibration accuracy analysis of SWAT model results of Figure 3

\begin{tabular}{lrlll}
\hline & $\begin{array}{c}\text { Water } \\
\text { Elevation }\end{array}$ & TSS & TN & TP \\
\hline $\mathbf{R}^{\mathbf{2}}$ & 0.99 & 0.74 & 0.46 & 0.46 \\
NSE & 0.94 & 0.24 & -0.38 & -0.04 \\
RMSE & 2.53 & 0.82 & 0.34 & 0.01 \\
\hline
\end{tabular}

Table 3: Calibration accuracy analysis of CE-QUAL-W2 model results of Figure 4 


\subsection{Climate Change Scenario Analysis}

\subsubsection{Average Effect for Entire Simulation Period (2016 2095)}

Table 4 and Table5 show average values of lake input loading predictions estimated by SWAT model and in-lake concentrations estimated by CE-QUAL-W2 model under climate change scenarios, respectively. The RCP4.5 scenario shows higher flow rate and pollutant delivery to the Yongdam Lake though precipitation of RCP8.5 was estimated to be higher. This seems to be caused by increased evapotranspiration due to higher temperature of RCP 8.5 scenario as Yi et al reported before (YiH. S., KimD. S., HwanM. H., AnK. G., 2016). For inside the lake, RCP8.5 shows higher water level and water quality concentration in average. However, these two tables only show average values of entire simulation period. Therefore, it would be necessary to investigate dynamic behaviour of results more in detail to characterize responses for climate change scenarios and thus to develop appropriate counter measures.

\begin{tabular}{lcccc}
\hline RCP Scenario & $\begin{array}{c}\text { Flow Rate } \\
\left(\mathbf{m}^{\mathbf{3}} / \mathbf{s}\right)\end{array}$ & $\begin{array}{c}\text { Sediment } \\
\text { (ton } / \mathbf{y r})\end{array}$ & TN (ton $/ \mathbf{y r})$ & TP (ton/yr) \\
\hline RCP 4.5 & 8.03 & 1,645 & 653 & 28 \\
RCP8.5 & 7.89 & 1,553 & 655 & 27 \\
\hline
\end{tabular}

Table 4: Average Inflow and Pollutants Loading Rates from Basin Area Using SWAT Model under RCP4.5 and RCP8.5 Scenarios for 2016 2095

\begin{tabular}{lcccc}
\hline RCP Scenario & Water Level $(\mathbf{m})$ & TSS $\mathbf{( m g / L )}$ & TN $(\mathbf{m g} / \mathbf{L})$ & TP $\mathbf{( m g} / \mathbf{L})$ \\
\hline RCP 4.5 & 253.69 & 14.13 & 1.30 & 0.104 \\
RCP8.5 & 254.29 & 15.12 & 1.35 & 0.109 \\
\hline
\end{tabular}

Table 5: Average Water Level and Water Quality Concentrations using CE-QUAL-W2 Model under RCP4.5 and RCP8.5 Scenarios for 2016 2095

\subsubsection{Average Effects for Three Sub-Period (2025s, 2050s and 2080s)}

Table 6 shows detailed analysis of basin modelling results by dividing the total simulation period (2016 2095) in three different sub-periods as 2016 2035 (2025s), 2036 2065 (2050s) and 2066 2095 (2080s). Each year was also divided as wet season (May-October) and dry season (November-April) considering precipitation distribution conditions in Korea. During 2025s, RCP8.5 shows significantly higher average flow rate $\left(1.19 \mathrm{~m}^{3} / \mathrm{s}\right.$ or $\left.27.4 \%\right)$ and average pollutant loadings during wet season while dry season flow rate increase $\left(0.18 \mathrm{~m}^{3} / \mathrm{s}\right.$ or $\left.15.2 \%\right)$ for RCP8.5 was relatively lower. However, average TP loading rate only during dry season showed opposite trend in 2015 s and 2050s while the impact trend in 2080s are the same for all variables. During 2050s, flow rate becomes significantly lower (1.37 $\mathrm{m}^{3} / \mathrm{s}$ or $23.6 \%$ ) in RCP8.5. Consequently, all pollutant loadings were significantly lower in this period as well. Flow and loadings in 2080s showed similar pattern with 2050 s except TP in dry season. It is notable that a simple arithmetic average of variables of simulation results may lead inappropriate interpretation and thus methods to respond the impact of climate change may not be effective.

Figure 6 shows monthly variations of lake modelling results for the three different sub-periods. Water levels were higher for RCP8.5 for entire period and also for each sub period. It is notable that water quality of TSS, TN and TP are better for RCP8.5 during 2025s and 2050s except TSS in 2025s. Water quality for RCP8.5 are worse and difference from RCP4.5 results are the highest during 2080s where water level differences were at the minimum among three sub-periods. 
Serial Application of SWAT and CE-QUAL-W2 to Predict Water Quality Dynamics ... D. Seo et al.

\begin{tabular}{|c|c|c|c|c|c|c|c|c|c|c|c|c|c|}
\hline \multirow[b]{2}{*}{ Years } & \multirow[b]{2}{*}{ Months } & \multicolumn{3}{|c|}{$\begin{array}{l}\text { Flow } \\
\left(\mathrm{m}^{3} / \mathrm{s}\right)\end{array}$} & \multicolumn{3}{|c|}{$\begin{array}{c}\text { Sediment } \\
\text { (metric ton) }\end{array}$} & \multicolumn{3}{|c|}{$\begin{array}{l}\mathrm{TN} \\
\text { (ton) }\end{array}$} & \multicolumn{3}{|c|}{$\begin{array}{c}\mathrm{TP} \\
\text { (ton) }\end{array}$} \\
\hline & & 4.5 & 8.5 & $\%$ & 4.5 & 8.5 & $\%$ & 4.5 & 8.5 & $\%$ & 4.5 & 8.5 & $\%$ \\
\hline \multirow{2}{*}{$\begin{array}{c}2016 \\
- \\
2035\end{array}$} & $\begin{array}{l}\text { Nov. - Apr. } \\
\text { Dry season }\end{array}$ & 1.12 & 1.30 & 15.16 & 13.05 & 16.38 & 25.56 & 8.24 & 8.64 & 4.84 & 0.39 & 0.33 & -13.45 \\
\hline & $\begin{array}{l}\text { May. - Oct. } \\
\text { Wet season }\end{array}$ & 4.33 & 5.52 & 27.39 & 102.20 & 149.80 & 46.49 & 33.81 & 39.08 & 15.59 & 1.44 & 1.90 & 31.85 \\
\hline \multirow{2}{*}{$\begin{array}{c}2036 \\
- \\
2065\end{array}$} & $\begin{array}{l}\text { Nov. - Apr. } \\
\text { Dry season }\end{array}$ & 1.47 & 1.54 & 5.09 & 21.19 & 23.67 & 11.68 & 10.23 & 10.67 & 4.37 & 0.51 & 0.45 & -10.88 \\
\hline & $\begin{array}{l}\text { May. - Oct. } \\
\text { Wet season }\end{array}$ & 5.82 & 4.45 & -23.59 & 170.10 & 103.60 & -39.08 & 37.61 & 31.78 & -15.51 & 1.76 & 1.15 & -34.73 \\
\hline \multirow{2}{*}{$\begin{array}{c}2066 \\
- \\
2095\end{array}$} & $\begin{array}{l}\text { Nov. - Apr. } \\
\text { Dry season }\end{array}$ & 1.48 & 1.73 & 17.43 & 20.54 & 29.49 & 43.53 & 9.47 & 12.05 & 27.23 & 0.32 & 0.74 & 130.10 \\
\hline & $\begin{array}{l}\text { May. - Oct. } \\
\text { Wet season }\end{array}$ & 5.48 & 5.06 & -7.68 & 151.90 & 130.60 & -14.03 & 33.95 & 31.44 & -7.39 & 1.29 & 1.03 & -19.95 \\
\hline
\end{tabular}

Table 6: Average SWAT Prediction of RCP4.5 and RCP8.5 Scenarios for Sub-Periods
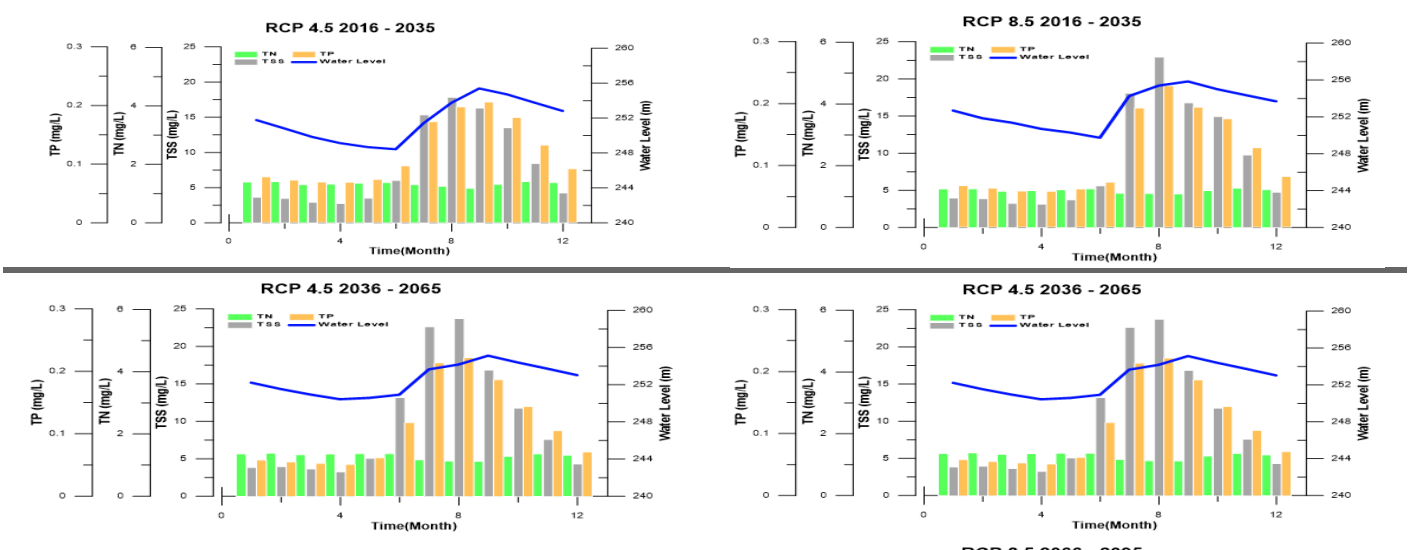

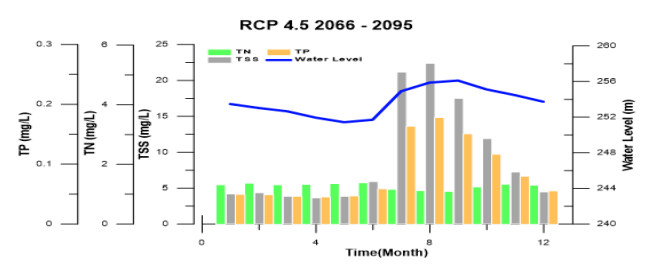

(a) RCP 4.5 scenario

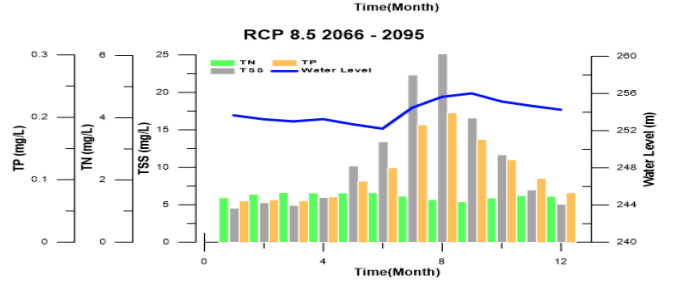

(b) RCP 8.5 scenario

Figure 6: Monthly Average of Water Level, TSS, TN and TP in the Yongdam Dam $2016 \sim 2035$ (2025s), $2036 \sim 2065(2050$ s) and $2066 \sim 2095$ (2080s) period for two climate change scenarios 


\begin{tabular}{c|c|c|c|c|c|c|c|c|c|c|c|c}
\hline & \multicolumn{3}{|c|}{ Elevation(m) } & \multicolumn{3}{c|}{ TSS(mg/L) } & \multicolumn{3}{c|}{ TN(mg/L) } & \multicolumn{3}{c}{ TP(mg/L) } \\
\hline Years & $\mathbf{4 . 5}$ & $\mathbf{8 . 5}$ & $\mathbf{\%}$ & $\mathbf{4 . 5}$ & $\mathbf{8 . 5}$ & $\mathbf{\%}$ & $\mathbf{4 . 5}$ & $\mathbf{8 . 5}$ & $\mathbf{\%}$ & $\mathbf{4 . 5}$ & $\mathbf{8 . 5}$ & $\%$ \\
\hline $\mathbf{2 0 1 6}-\mathbf{2 0 3 5}$ & 251.7 & 253.0 & -0.50 & 8.17 & 9.24 & -13.1 & 1.33 & 1.20 & 9.70 & 0.119 & 0.115 & 3.30 \\
\hline $\mathbf{2 0 3 6}-\mathbf{2 0 6 5}$ & 252.6 & 253.6 & -0.40 & 10.02 & 8.80 & 12.2 & 1.30 & 1.29 & 0.76 & 0.112 & 0.101 & 9.80 \\
\hline $\mathbf{2 0 6 6}-\mathbf{2 0 9 5}$ & 253.7 & 254.0 & -0.14 & 9.15 & 11.02 & -20.4 & 1.29 & 1.49 & -15.5 & 0.087 & 0.114 & -31.0 \\
\hline
\end{tabular}

Table 7: Average of Water Level, TSS, TN and TP in the Yongdam Dam during 2025s, 2050s and 2080s period for two climate change scenarios

\section{Conclusions}

The SWAT model and the CE-QUAL-W2 model were applied in series in the basin area and the Yongdam Lake, respectively. Calibrations were performed for the six years between 2010 and 2015 while major calibrations were focused in latter three period assuming the first three years as warming periods. Physical calibrations results of basin area flow rate and water level in the lake were acceptable as their $\mathrm{r}^{2}$ values were 0.86 and 0.99 , respectively. However, calibration results of pollutant load from basin area and water quality inside lake were relatively poor. This is due to either lack of pollutant information or appropriate field monitoring data.

Two climate change scenarios, RCP4.5 and RCP8.5, were applied for 2016 2095 period and results were analysed. When results of entire modelling period were averaged, RCP4.5 scenario shows higher flow rate and pollutant loading rate to the Yongdam Lake though precipitation of RCP8.5 was estimated to be higher. This seems to be caused by increased evapotranspiration due to higher temperature of RCP 8.5 scenario. For inside the lake, RCP8.5 shows higher water level and water quality concentrations in average.

Further analyses were performed by dividing total simulation period (2016 2095) into three different sub-periods as 2016 2035 (2025s), 2036 2065 (2050s) and 2066 2095 (2080s). Each year was also divided as wet season (May-October) and dry season (November-April). During 2025s, RCP8.5 shows significantly higher flow $\left(1.19 \mathrm{~m}^{3} / \mathrm{s}\right.$ or $\left.27.4 \%\right)$ and pollutant loadings during wet season while dry season flow increase $\left(0.18 \mathrm{~m}^{3} / \mathrm{s}\right.$ or $\left.15.2 \%\right)$ for RCP8.5 was relatively lower. However, TP loading in dry season showed different patterns during 2015s and 2050s. During 2050s, flow rate becomes significantly lower $\left(1.37 \mathrm{~m}^{3} / \mathrm{s}\right.$ or $\left.23.6 \%\right)$ in RCP 8.5 . Consequently, all pollutant loadings were significantly lower in this period as well. Flow and loadings in 2080s showed similar pattern with 2050s except TP in dry season. It should be emphasized that a simple arithmetic average of variables of simulation results may lead inappropriate analysis thus developed methods under this assumption to respond the impact of climate change may not be effective. Therefore, it would be necessary to investigate dynamic behaviour of results more in detail to characterize responses to climate change scenarios and thus to develop appropriate counter measures. In the case of Yongdam Lake, input of pollutant loading tend to decrease in dry season and increase in flood season. Therefore, TSS and TP concentration tend to be higher in the summer monsoon period. However, TN showed different behaviour as they are not adsorbed to particulate material. It was notable that pollutant loading is intensified during August $\sim$ October period. According to climate change scenario, number of raining day decrease while rainfall intensities tend to increase. This means that, for 
the study area, effect of drought and flood will become more serious, respectively in the future. Therefore, it would be necessary to develop appropriate water management alternatives by considering water quantity and quality simultaneously in both dry and flood seasons to prepare for climate change effect in the study area.

\section{Acknowledgement}

This research was supported by the Korean Ministry of the Environment (Project No. RE201305039).

\section{References}

Ahn, S., Kim, H., Yoon, W., \& Kim, J. (2013). Evaluation of Suspended Solids and Eutrophication in Chungju Lake Using CE-QUAL-W2. Journal of Korea Water Resources Association, (pp. Vol. 46, No. 11, pp. 1115-1128).

Chung, W., Park, H., Kim, Y., \& Yoon, W. (2007). Application of CE-QUAL-W2 to Daecheong Reservoir for Eutrophication Simulation. Journa of the Korean Society on Water Quality, (pp. Vol. 23, No. 1, pp. 52-63).

Cole, T., \& Wells, S. (2016). CE-QUAL-W2: A two dimensional, Laterally averaged, Hydrodynamic and Water quality Model, Version 4.0 user's manual. Vicksburg, MS.: U.S Army Corps of Engineer.

IPCC. (2014). IPCC 2014: Climate Change 2014: Synthesis Report, Contribution of Working Groups I, II and III to the Fifth Assessment Report of the Intergovernmental Panel on Climate Change [Core Writing Team, R.K. Pachauri and L.A. Meyer (eds.)]. Geneva, Switzerland: IPCC.

KMA. (2014). Korean Climate Change Assessment Report. Korea Meteorological Administration .

Neitsch, S. L.; Arnold, J. G.; Kiniry, J. R.; Williams, J. R.;. (2011). Soil and water assessment tool theoretical documentation version 2009. Texas Water Resources Institute.

NIER. (2017). Water Information System (WIS), Ministry of Environment. Retrieved from http://water.nier.go.kr/

WAMIS. (2017). Water Resources Management Information System, Ministry of Land, Infrastructure, and Transport. Retrieved from http://www.wamis.go.kr/

Yi, H., Kim, D., Hwan, M., \& An, K. (2016). Assessment of Runoff and Water temperature variations under RCP Climate Change Scenario in Yongdam dam watershed. Journal of Korean Society on Watre Environment, (pp. Vol. 32, No. 2, pp. 173-182). 